\title{
The state of infrastructure facilities of the Kola Peninsula for the independent life of people with disabilities
}

\author{
Galina Zhigunova* \\ Murmansk Arctic State University, 183038 Murmansk, Russia
}

\begin{abstract}
The article examines the problem of accessibility of objects of social infrastructure of the Kola Peninsula for disabled people. The study was based on the method of monitoring the state of infrastructure in 13 settlements of the region, in which 701 objects were examined for accessibility for the disabled. As a result of observation, the objects were divided into accessible, conditionally accessible and inaccessible; accessibility indices were calculated for different areas of activity. The study revealed uneven processes of creating an accessible environment in the Kola North, depending on the type of settlements and the location of objects. Most of the accessible infrastructure facilities are located in cities on central streets and are aimed at access mainly for people with musculoskeletal disorders. Social protection institutions, banks and post offices provide access for people with disabilities best of all. In other areas of activity, objects are only partially accessible.
\end{abstract}

\section{Introduction}

In Russia, regular measures are currently being held to ensure conditions for the independent lifestyle of people with disabilities.

The environment has a key role in the daily life of the disabled persons. This was stated back in 1982 in the World Programme of Action concerning Disabled Persons, by its resolution $37 / 52$. As a result of the deprivation of the opportunity to participate in society, "a person is handicapped," is indicated in this document [1].

An inaccessible environment divides and segregates people depending on the presence and absence of access to social infrastructure. R. Imre, studying urban space, calls this phenomenon "distinctive spatial demarcation and exception" [2, p. 232].

The social environment directly or indirectly sets the boundaries for people with disabilities and the ability to use publicly available social benefits. Thus, the environment determines the measure of self-realization of these people and affects their quality and lifestyle, daily practices and relationships with other fellow citizens.

In this regard, this study aims to identify infrastructural barriers to disability by determining the condition and level of accessibility of social environment facilities using the example of one of the Russian regions.

* Corresponding author: galina-zhigunova@yandex.ru 
It can be argued that a barrier-free environment is a kind of barometer of the state of public institutions and society as a whole.

From how much the society takes into account the need for participation in it of people with disabilities, one can judge the state of inclusive processes and the observance of legally established human rights in it.

\section{Research methodology}

To ensure a normal standard of living for people with disabilities, it is necessary that the social environment maintain and provide adequate access to basic urban and social resources, including employment, education, medical care, social security, recreation, etc. $[3]$.

The removal of urban planning barriers is an important point in this matter, which gives people with disabilities access to many social resources, as well as work, communication, social interactions. It also makes it possible to improve the material condition and reduce the dependent burden on the employed population, contributes to the social independence of people with health disorders.

It also provides an opportunity to improve the material situation Eliminating urban planning barriers is an important point in this matter, which gives people with disabilities access to many social resources, as well as work, communication and social interactions.

In Russian society, the role of the environment has not been understood as key for a long time. Historically, it has been perceived that persons with disabilities are primarily guardianship objects that need basic needs. For this purpose, a paternalistic model of social protection was formed in the USSR, in the framework of which persons with disabilities received social support in the form of pensions and benefits. Disability was understood as a personal tragedy caused by a person 's bodily abnormality and functional limitations, and persons with disabilities themselves were in a dependent position and perceived as dependants unable to work.

Under the influence of the international policy on persons with disabilities, since the mid-1990s the understanding of disability in Russia has gradually changed in the direction of its awareness as a social rather than a purely medical phenomenon.

As stated in the Convention, people have an equal right to an independent lifestyle and full participation in all its aspects. At the same time, an independent lifestyle presupposes the right of personal choice and minimization of dependence on other persons in the exercise of their civil rights [4].

From the late 90 s to the present, a large number of regulatory documents have been adopted aimed at implementing the provisions of the Convention to remove social barriers and ensure an independent life for people with disabilities.

From 2011 to the present, the creation of an accessible environment for disabled citizens in the Russian Federation is carried out through the measures of the State Program "Accessible Environment" [5].

The activities of this Program are aimed at transforming the priority spheres of life of people with disabilities: health, culture, social protection, education, information, employment, transport and pedestrian infrastructure, sports and physical education.

Unfortunately, this program, forming a barrier-free environment, does not affect many areas of people's daily activities. And the transformation of priority social facilities is extremely uneven in activities in different areas, due to uneven funding [6]. Researchers also conclude that the measures implemented by the program do not have integrity and consistency, do not use innovations and do not take into account the subjective differences between different categories of disabled people [7]. 
Creation of equal conditions for people with disabilities today goes in two ways. One of them provides for the universal design of objects to facilitate their convenient use by all people, and the second - a reasonable adaptation of the environment for people with disabilities with special needs.

In creating an accessible environment, a targeted approach is currently widely used in Russia. This approach involves the creation of special conditions for people with disabilities with certain types of violations only in their places of residence and employment, along with the transformation of priority objects. So, for example, - indicates L.N. Natsun, if visually impaired people live in the city's microdistrict, the environment of the microdistrict must be adapted for the visually impaired [8]. Accordingly, if the blind or visually impaired do not live in this territory, such transformations are inappropriate. Despite the fact that this approach allows more efficient use of financial resources to create an accessible environment, it can only be used at the initial stage of transformation. In the future, if the environment is not equipped, it will continue to be a source of segregation and exclusion, preventing people with a wide variety of types of violations from accessing the territory.

A good example of creating an inclusive urban environment, which I would like to mention here, is General Gordon Square in London. It was designed in 2011 by landscape architect Gustafson Porter to provide equal opportunities for all visitors in this place $n$ this place [9].

During the implementation of the Accessible Environment program in modern conditions, another way to create a barrier-free environment has also become widespread in Russia - by delivering services to people with disabilities. This way allows people with disabilities to enjoy public goods, but at the same time they still remain dependent on others. In this regard, bringing social infrastructure in line with the principles of accessibility is an important measure necessary to ensure a truly independent life for people with disabilities.

Currently, Russian researchers note a large number of difficulties that exist in ensuring an accessible environment for citizens with disabilities in the regions.

According to the monitoring of the accessibility of priority objects of social and urban infrastructure conducted by the Information Communications Center in 2015 in all Russian regions (3,000 objects were examined in 85 regions), the top ten most accessible cities included large Federal Centers and cities with a population of over one million: Moscow, Krasnodar Territory, Republic of Tatarstan, St. Petersburg, Tyumen region, Belgorod region and others. And most cities are among the lagging [10].

Researchers call sports facilities, learning cultures, and housing as inaccessible for people with visual impairment and musculoskeletal impairment $[11, \mathrm{p} .8]$, social security facilities [12], and others.

In the course of the author's survey conducted in 2019 in the Murmansk region among the disabled (interview method, $\mathrm{N}=30$ with disabled people - support workers, people with hearing, vision and general diseases, the age of the respondents was from 16 to 71 years old), in the region it was revealed an acute problem of an inaccessible environment. This is the lack of special devices for disabled people when entering residential and public buildings or their inadequacy to accessibility requirements, the lack of well-thought-out walking routes and, in general, an insufficient level of preparedness of the social environment for the needs of disabled people. The informants drew attention to the fact that successful participation in society for people with disabilities today is possible only with the help of outside help. People with musculoskeletal and mental disorders, as well as blind and visually impaired, require constant accompaniment, without which they will not be able to move around the streets on their own. The respondents see the reasons for the inaccessible environment in the Kola North in the low rate of infrastructure transformation 
and the insufficient implementation of the state program "Accessible Environment". Within the framework of this program, according to the respondents, practically nothing has been done in the region, except for the installation of ramps in public places [13].

As the reasons for the existence of barriers in Russia, it is necessary to indicate an illconceived urban development policy, lack of funds, lack of control over the implementation of standards for accessibility to construction sites; lack of interest of departments and the whole society in solving the problems of citizens with disabilities; lack of consistent actions and measures to expand information accessible to persons with disabilities [13, p. 11].

The obtained research data show the urgency of the problem of creating an accessible infrastructure for people with disabilities in Russia and the need to assess the measures taken in this direction.

In 2018-2019, the author carried out observations of the infrastructure of the urban and rural environment of the Kola Arctic in order to identify the level of its accessibility for disabled people.

The selection of settlements was determined by their location, type and status, and ensured representation in the sample of all municipalities and districts in the region $(\mathrm{N}=$ 13). Among them there are 7 cities and 6 rural settlements.

In the rurals the observation was continuous; in the cities, the bulk of the objects was examined (at least $70 \%$ ).

The object of observation was the elements of the equipment of the entrances to the buildings and the presence of inclusive conditions of public areas. The subject is their compliance with accessibility criteria for people with disabilities (for the visually impaired, wheelchair users and those with musculoskeletal disorders). The accessibility criteria are defined by regulatory documents in this area, according to which the observed objects were divided into three groups - accessible, conditionally accessible and inaccessible.

A total of 701 objects were covered by observation (569 of them in cities and 132 in rurals). In total, 266 objects of observation belonged to the category of priority, allocated by the "Affordable Environment" Program (216 - in urban, 50 - in rural settlements) - stadiums and other sports facilities; polyclinics, hospitals and pharmacies; train stations; cinemas, theaters and houses of culture; centers of social services for the population; kindergartens, schools, colleges and higher education institutions; sidewalks and footpaths. 465 objects belonged to various spheres of daily activity: trade and entertainment, postal and banking services, services, food, walking on the street (parks, squares, playgrounds), administrative practice (administration buildings, police, courts, registration of civil acts, migration and passport registration and others).

\section{Research results}

During the monitoring process, a total of $20.4 \%$ of accessible, $14.6 \%$ of conditionally accessible and $65 \%$ of inaccessible objects were identified. The barrier index of the region's infrastructure objects excluding settlement type was -0.44 .

Among urban infrastructure facilities of the Murmansk region $23.7 \%$ is available, $16.2 \%$ is conditionally available, $60.1 \%$ of facilities are unavailable. Among rural objects, $6 \%$ is available, $7.6 \%$ is conditionally available, $86.4 \%$ of objects are unavailable (fig. 1 ). 


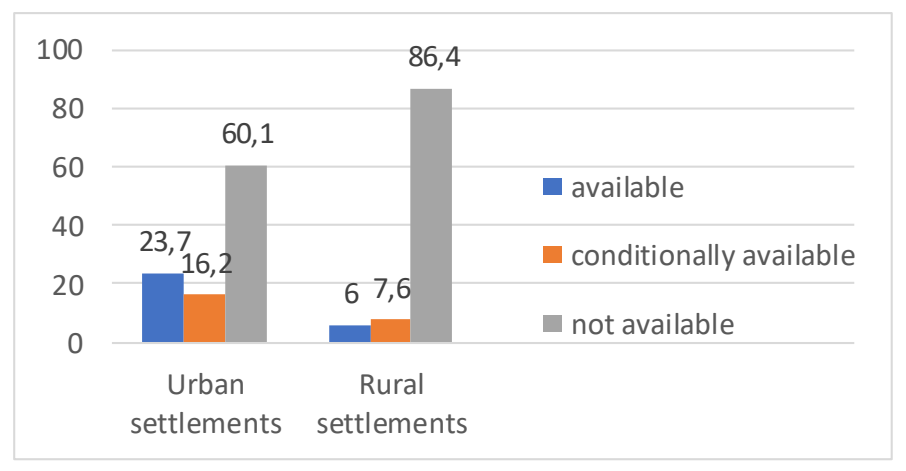

Fig. 1. The state of accessibility of urban and rural infrastructure, $\%$

The vast majority of accessible facilities are focused only on people with disorders of the musculoskeletal system and wheelchair users, while for the visually impaired and blind, $6 \%$ are available in cities and $1 \%$ in rurals.

The results of comparing the level of accessibility of objects in cities and rural areas revealed the uneven development of the barrier-free environment in the region was revealed, depending on different types of settlements. The barrier index for cities was -0.36 and for rural settlements-- 0.8 (where 1 is fully accessible and -1 is completely inaccessible). In cities, the availability of facilities for the disabled is somewhat higher in non-priority areas of activity, while in rurals, on the contrary, it is higher in priority areas. The barriers index of priority urban objects is -0.39 and non - priority -0.3 ; priority rural objects -0.7 , non-priority -0.87 .

The condition of the observed objects in the Murmansk region is satisfactory only in a few spheres: social protection, postal services, banks that have a positive accessibility index. Parks and transport infrastructure (train and bus station buildings) occupy a neutral position, while all other spheres have a negative accessibility index (table 1).

Table 1. Index of accessible environment for the kola peninsula for disabled

\begin{tabular}{|c|l|c|}
\hline $\mathbf{R}$ & \multicolumn{1}{|c|}{ Object name } & $\begin{array}{c}\text { Availability } \\
\text { Index }\end{array}$ \\
\hline 1 & Social protection organizations & 0,46 \\
\hline 2 & Postal service & 0,15 \\
\hline 3 & Bank offices & 0,02 \\
\hline 4 & Parks & 0 \\
\hline 5 & Passenger transport offices & 0 \\
\hline 6 & Health services & $-0,06$ \\
\hline 7 & Trade and entertainment facilities & $-0,38$ \\
\hline 8 & Culture and art organizations & $-0,48$ \\
\hline 9 & Other buildings (administrative and departmental) & $-0,56$ \\
\hline 10 & Food points & $-0,63$ \\
\hline 11 & Sports objects & $-0,65$ \\
\hline 12 & Educational organizations & $-0,67$ \\
\hline 13 & Service and service institutions & $-0,71$ \\
\hline
\end{tabular}




\begin{tabular}{|c|l|c|}
\hline $\mathbf{R}$ & \multicolumn{1}{|c|}{ Object name } & $\begin{array}{c}\text { Availability } \\
\text { Index }\end{array}$ \\
\hline 14 & Playgrounds for children & $-0,82$ \\
\hline
\end{tabular}

Positive index of accessibility in urban settlements have social security institutions, banks (indexes 0.5 ) and post offices (index 0.4); in rural settlements - only health care institutions (index 0.2). Transport offices in cities and social protection offices in rural areas are partially accessible. The rest of the infrastructure is inaccessible (fig. 2).

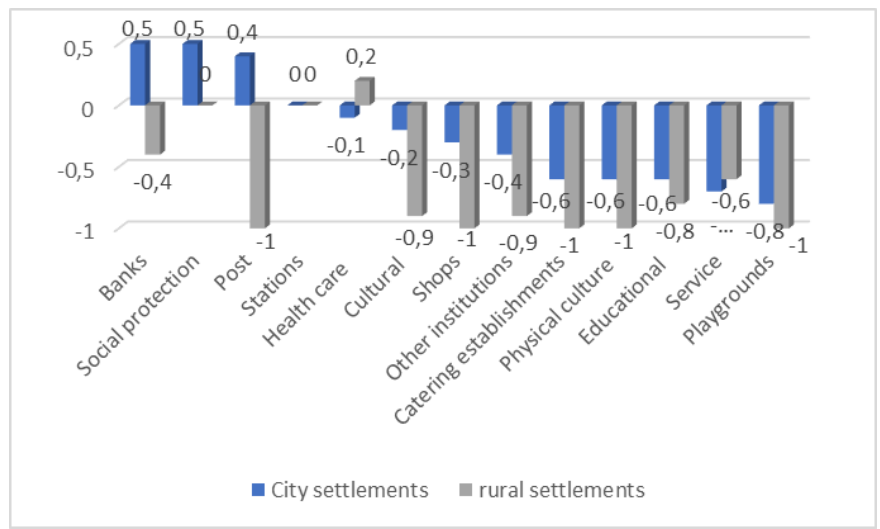

Fig. 2. Availability indices for infrastructure facilities in cities and villages.

In cities, playgrounds (index -0.8), service services (index -0.7), educational institutions, food outlets, sports facilities (indexes at -0.6) are the worst accessible.

Cultural institutions, other organizations (at -0.9 each), educational institutions $(-0.8)$, and objects of the service sector (-0.6) are inaccessible in rural settlements of the region. Playgrounds, public catering, educational and sports institutions, post offices, shops are completely inaccessible (-1 each).

Significantly lower the level of accessibility of small institutions compared with large network organizations, as well as of objects located in the outlying territories compared with the main streets.

\section{The discussion of the results}

The study showed that the most common problem of infrastructure facilities in the Kola North is the poor condition of ramps or their absence, narrow doorways, obstacles at the entrance, the absence of handrails, call buttons, tactile stripes and braille, mechanically opening doors, and more. In winter season snow and snow problems are added, as a result of which the level of accessibility of social facilities becomes close to zero.

Examples of non-compliance with the quality requirements of installed elements of an accessible environment can serve emergency ramps of the store "Family" in Severomorsk, registry office in Monchegorsk (narrow "ramps" covered with slippery tiles, without handrails, a tree grows in one of them), Police of Zapolyarny city (the ramp is covered with snow, icicles hang from the roof above it), the Jungle cafe in Apatity (obstacle from the ramp to the entrance to the building) (fig. 3). 


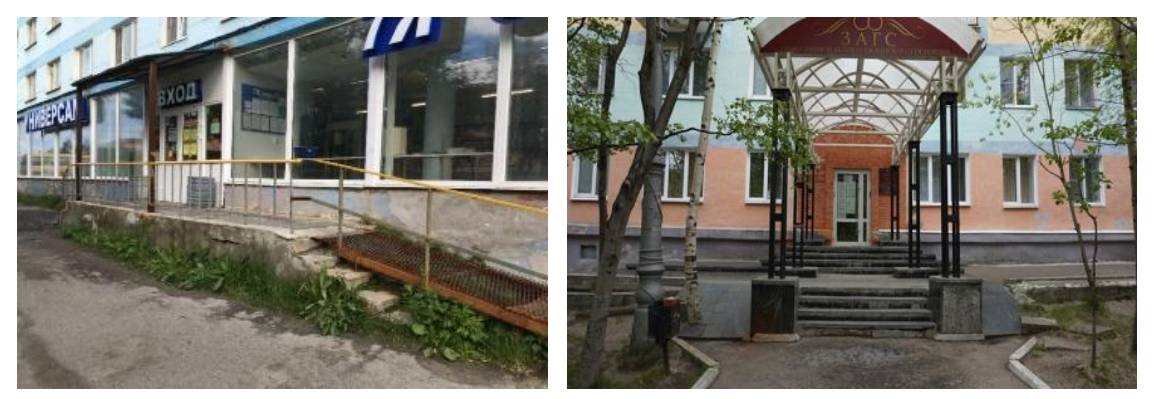

Fig. 3. Examples of noncompliance with the installation requirements of the available environment elements

As for the pedestrian infrastructure, in all the observed settlements it is also best organized on the central streets, where there are asphalted and well-groomed paths and sidewalks equipped with sound-activated traffic lights, exits from curbs, accessible pedestrian crossings. Accordingly, the state of pedestrian infrastructure on the outskirts is much worse, which complicates the life of people with limited mobility who do not live in the center of the city or village.

In general, the environment of the Kola North is characterized by the presence of fragmented and randomly located accessible facilities and the absence of a holistic system of accessible urban planning environment for the disabled. The social infrastructure of the surveyed territories of the region only partially corresponds to the principles of accessibility for the disabled: first of all, in social protection facilities, postal and banking services. At the same time, there are twice as many accessible infrastructure in cities than in villages.

\section{Conclusions}

All this shows that at present on the Kola Peninsula, an important task is the problem of equipping social infrastructure for disabled people. To solve it, it is necessary, in addition to financial investments, the formation of a socially responsible attitude to removing infrastructure barriers, as well as the initiation of a variety of inclusive practices of citizens and professional communities in achieving equal rights for people with disabilities in the absence of conditions for their independent life.

Removing barriers of exclusion will not only improve the quality of life of people with disabilities and the local population, but will also help to enhance the image of the Kola region and develop its social capital.

\section{References}

1. World Programme of Action concerning Disabled / adopted by the General Assembly on 3 December 1982, https://www.un.org/development/desa/ disabilities/resources/world-programme-of -action-concerning-disabled-persons.html

2. R. Imrie, Urban Studies, 38 (2), 232 (2001)

3. N. N. Sze, K. M. Christensen, IATSS Research, 41 (2), 66 (2017).

4. Convention on the Rights of Persons with Disabilities and Optional Protocol (2006). https://www.un.org/disabilities/documents/convention/convoptprot-e.pdf

5. Gosudarstvennaya programma Rossijskoj Federacii «Dostupnaya sreda» na 2011 2020 gody (1.12.2015, N 1297), https://base.garant.ru/77673671/.

6. A. A. Nikonova, Vestnik Tomskogo gosudarstvennogo universiteta, 10 (2016) 
7. L. A. Migranova, YU. S. Nenahova, Narodonaselenie , 1, 107 (2015).

8. L. N. Nacun, Problemy razvitiya territorii - Territory development problems 2, 95 (2019)

9. Ch. Bates. Sociological review 66 (5), 984 (2018).

10. Nacional'nye rejting: Dostupnaya sreda, http://russia-rating.ru/info/8288.html

11. A. A. Shabunova, L. N. Fahradova, Voprosy territorial'nogo razvitiya, 3, 2 (2014).

12. N. YU. Shcheka, YU. S. Gontoruk, Baltic State Journal, 10 (1), 341 (2018).

13. G. V. Zhigunova, Baikal Research Journal, 10(4) (2019) 